\title{
Por uma Economia Política da Ciência e Tecnologia
}

\section{Theotônio dos Santos}

Professor visitante da Universidade do Estado do Rio de Janeiro (UERJ), Rio de Janeiro, Brasil, professor emérito da Universidade Federal Fluminense (UFF), Presidente da REGGEN, Presidente do Conselho do CEPPES, Prêmio Mundial de Economia Marxiana de 2013 (WAPE).

\section{Resumo}

A partir de uma crítica do neoliberalismo como proposta teórica e prática, busca-se demonstrar os limites de uma ideologia que não reconheça que o enorme desenvolvimento das forças produtivas alcançado com a revolução científico-técnica entra em contradição com as relações de produção apoiadas na ideia da propriedade privada dos meios de produção e de um livre mercado produzido como um mito a serviço de forças conservadoras que levaram a humanidade a duas guerras mundiais no século XX e uma guerra anticolonial depois da II Guerra Mundial que coloca na primeira plana da economia mundial a maioria da população da terra.

Palavras-chave: economia política, neoliberalismo, políticas públicas, ciência e tecnologia.

\section{Resumen}

A partir de una crítica al neoliberalismo como propuesta teórica y práctica, se busca demostrar los límites de una ideología que no reconoce que el enorme desarrollo de las fuerzas productivas, alcanzado con la revolución científico-técnica, entra en contradicción con las relaciones de producción apoyadas en las ideas de propiedad privada de los medios de producción y de libre mercado, producidas como un mito a servicio de fuerzas conservadoras que llevaron la humanidad a dos guerras mundiales en el Siglo XX y una guerra anticolonial tras la II Guerra Mundial, al colocar así en la primera plana de la economía mundial la mayoría de la población de la tierra.

Palavras llave: economía política, neoliberalismo, políticas públicas, ciencia y tecnología. 


\section{Abstract}

With a critique to neoliberalism as theoretical and practical proposal, this paper aims to demonstrate the limits of an ideology that does not recognize that the enourmous development of the productive forces, achieved by the scientific-technical revolution, becomes contradictory to relations of production based on the ideas of private property of the means of production and of free market, produced as a myth at the service of conservative forces that led humanity to two world wars in the XX century and an anticolonial war after World War II, bringing most of the world's population to the forefront of the global economy.

Keywords: political economy, neoliberalism, public policies, science and technology. 
$\mathrm{P}$ ara poder discutir a necessidade de sistematizar os princípios que devem orientar uma economia política da ciência e tecnologia, nas condições socioeconômicas atuais, temos que dar alguns passos atrás. A própria Economia Política foi questionada por uma ampla campanha ideológica, política e teórica de origem conservadora ou mesmo reacionária que se denominou em nossos países "neoliberalismo", apesar de que sua correta designação seria de um ultraconservadorismo. O prefixo "neo" apareceu para confundir, tentando apresentar como algo novo uma tentativa de fazer ressurgir uma problemática inteiramente superada e de transformar em arcaico o que era e é o mais avançado esforço intelectual: a crítica à economia política iniciada por Karl Marx em O Capital, livro que quase todos os expoentes do "neo" confessavam nunca ter lido.

Para abrir o caminho para uma reflexão correta, temos que limpar o ambiente intelectual e demonstrar a petição de princípio do pensamento "teórico" neoliberal que se impôs nos últimos 30 anos no plano político, nos meios de comunicação e até na academia. Este pretenso projeto teórico procurou voltar às premissas básicas do liberalismo, estabelecidas no século XVIII. Pretendeu demonstrar que o "livre" mercado é um produto da "natureza humana", fundada, segundo os filósofos liberais, na ideia do "indivíduo possessivo" como plena expressão da natureza humana.

Além do evidente conteúdo ideológico desta construção “teórica”, já demonstrado por vários autores, entre os quais me incluo, ela entra em contradição com o caráter monopolista do mercado atual e sobretudo com o capitalismo de Estado desenvolvido no qual se fundamenta o capitalismo contemporâneo. Se a hipótese do livre mercado poderia ter algum sentido prático no século XIX para impor o domínio do capital sobre a economia mundial, no século XX e mais ainda no século XXI é uma aberração inútil que entra em choque com os fatos dia após dia. Daí o fracasso do neoliberalismo e do "pensamento único" para inspirar políticas econômicas coerentes.

Em meu estudo sobre a teoria e a prática do neoliberalismo demonstro como as políticas econômicas de inspiração neoliberal aumentaram irresponsavelmente o déficit público e portanto a dívida pública e a intervenção do Estado na economia (diminuindo a despesa social do Estado contemporâneo mas aumentando de maneira explosiva as despesas financeiras e militares). Ao mesmo tempo, os governos neoliberais criaram gigantescos déficits comerciais, por um lado, e enormes superávits comerciais, por outro, que introduziram um desequilíbrio brutal na economia mundial. Deve-se notar ainda a divisão do mundo entre credores e devedores na medida em que estes deficits e superávits tendem a converter-se em estruturais e permanentes e portanto acumulativos gerando oscilações espantosas nos valores das moedas locais e nas moedas usadas como reservas fiduciárias.

Estes desequilíbrios fiscais e comerciais conduziram portanto a desequilíbrios monetários brutais e a uma oscilação das divisas internacionais completamente dependentes das intervenções estatais e dos jogos monopolistas e especulativos que nenhum mercado "livre" pode, nem de longe, regular. Este grau de desequilíbrio só pode ser alcançado por via da mais violenta intervenção estatal.

Junto a essa desqualificação da tentativa infantil de diminuir o papel do Estado no mundo do capitalismo de Estado, o fracasso neoliberal nos leva a revisar o entendimento sobre o caráter do próprio Estado contemporâneo. Este gigante em constante crescimento cria uma situação de forte contradição entre seu papel histórico concreto 


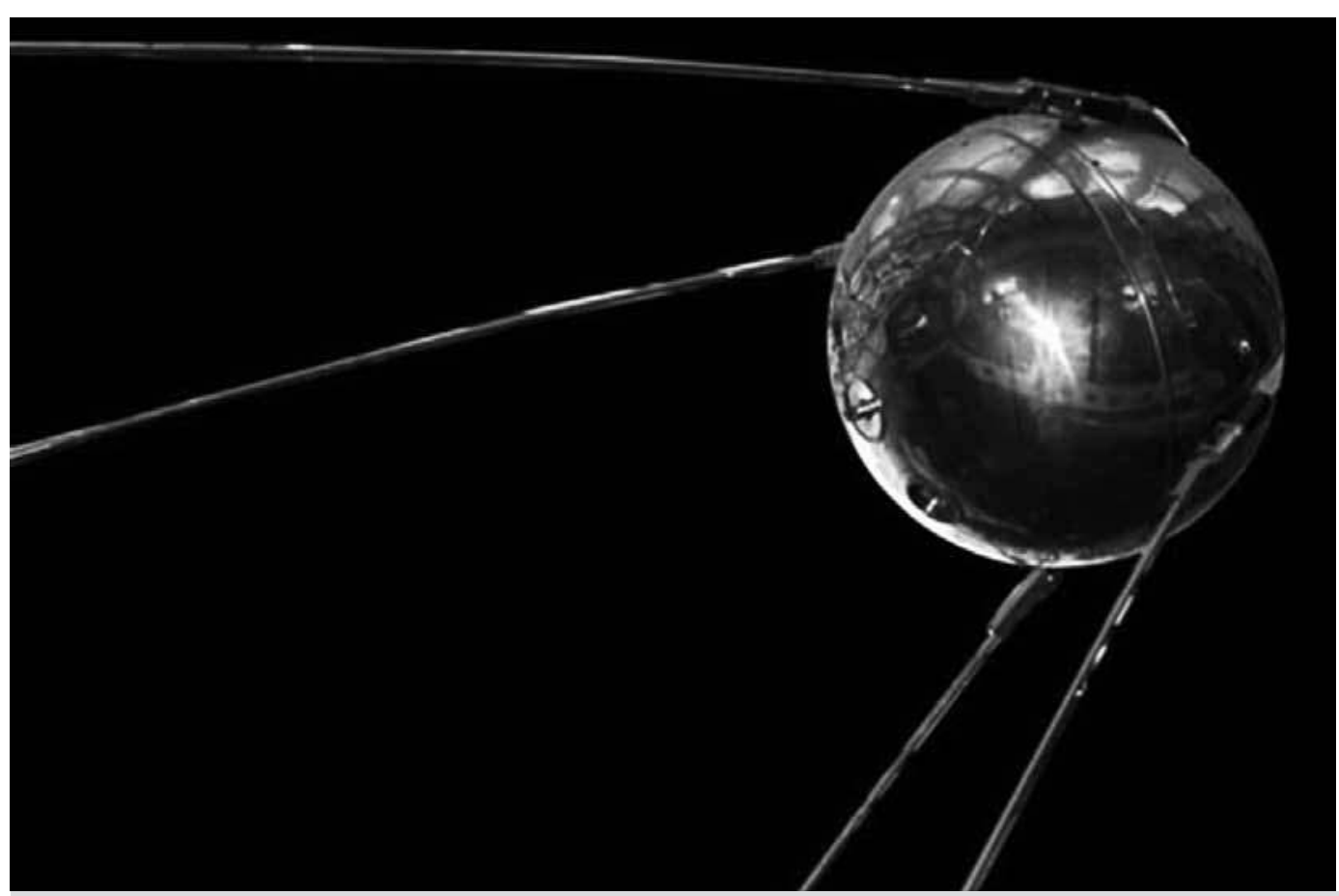

Sputnik (Fonte: http://www.apolol 1.com).

e as categorias ideológicas e pretensamente científicas que predominam nos meios responsáveis por tomadas de decisão que envolvem o destino da humanidade.

A segunda tese - que apresentamos em vários livros - se refere à relação entre os regimes de força, fascistas e para-fascistas, e o domínio ideológico e político do neoliberalismo. Não foi uma coincidência que o desmoralizado grupo da Universidade de Chicago encontrou sua oportunidade histórica e o primeiro governo que os inseriu no mundo econômico real através do regime fascista de Augusto Pinochet no Chile. Nem é menos verdade que os governos de Thatcher e Reagan, que propagaram pelo mundo inteiro estas propostas proto-modernas, se impuseram através de violentos enfrentamentos com o movimento sindical e com os movimentos sociais de forte conteúdo popular, através de formas bestiais de autoritarismo político.

Estabelecemos assim uma cuidadosa análise da correlação direta entre o terror de Estado e as políticas neoliberais que retiraram dos trabalhadores direitos historicamente conquistados, rebaixando drasticamente seus salários ao combinar repressão estatal com repressão econômica através das recessões identificadas com suas políticas econômicas, com seu séquito de desemprego e desesperança.

Nosso livro intitulado Do Terror à Esperança: Auge e Declinio do Neoliberalismo' (editado em português por Ideias \& Letras e em castelhano pela Monte Ávila Editora e Banco Central de Venezuela, além da edição em mandarim pela Academia de Ciências Sociais da China) contribui assim a um entendimento significativo do período recessivo da economia mundial entre 1967 a 1994, tema que analisamos no quadro das ondas longas de Kondratiev, contribuição teórica e econométrica do economista russo cuja vigência restabelecemos na década do 1970 junto com Ernest Mandel, André Gunder Frank, Christopher Freeman, Immanuel Wallerstein, Giovanni Arrigui, Amilcar Herrera, Carlota Pérez e tantos outros.

Acreditamos ter dado mais substância a essa grande contribuição teórica ao demonstrar a relação entre as "ondas longas" - designação dos ciclos longos que se 
impuseram por razões metodológicas e teóricas - e os paradigmas tecnológicos cujo caráter sistêmico impõe limites de tempo ao funcionamento da economia. Estes paradigmas tecnológicos são cada vez mais articulados, por sua vez, com o desenvolvimento dos paradigmas científicos revelados por Thomas Khun e estão profundamente associados ao movimento das inovações primárias, secundárias e terciárias que se sucedem dentro de cada paradigma tecnológico. Carlota Pérez, por sua vez, estudou com muita lucidez a relação entre estes fenômenos e os ciclos financeiros em um livro excelente.

Devemos em grande parte esta compressão sistêmica que articula os ciclos longos e a lógica das inovações revolucionárias produzidas pela atividade do conhecimento (atividade cada vez mais organizada pela humanidade em seu conjunto e desfrutada pelos poderes monopólicos concentrados pelo capital) às descobertas do economista austríaco Joseph A. Schumpeter. Tais descobertas teóricas foram muito desenvolvidas por seus discípulos nos anos 1970-1990 e serviram de base, em grande parte das políticas industriais articuladas pela Comunidade Europeia. Da mesma maneira, o enfoque schumpeteriano influenciou as políticas econômicas do Estado japonês, cujo white paper (termo de origem inglesa que se refere a documentos oficiais) de 1947 foi elaborado por Shigeto Tsuro, discípulo de Schumpeter e grande marxista japonês que tentou sempre articular as contribuições desses dois pensadores. Em minha última visita à China, escutei a revelação do Presidente da Academia de Ciências Sociais de Xangai que o governo de Xangai, cuja política econômica era dirigida por ele, inspirou-se nos ciclos longos de Kondratiev e em nossos estudos sobre sua atualidade, com enorme sucesso por sinal.

Armados destes elementos essenciais, cabe-nos assim avançar na análise da nova fase da economia capitalista mundial, na qual entram em crise definitiva as falsas interpretações e soluções impostas no período do auge neoliberal. $O$ fracasso destas análises [falsas] teve como evidência colossal a crise mundial desatada no segundo semestre de 2008. Se é verdade que este período crítico não teve o caráter final que muitas análises tentaram insinuar ou mesmo explicitar, o que foi fortemente contestado por nós, ele demonstrou, com enorme violência, algumas das teses derivadas da construção teórica em desenvolvimento que resumimos neste artigo.

Chamamos a atenção - em vários estudos - para o papel particularmente impactante da revolução científico-técnica sobre a articulação entre o desenvolvimento das forças produtivas e a sobrevivência de relações de produção arcaicas, baseadas na hegemonia da propriedade privada, que já se encontravam superadas desde a Primeira Guerra Mundial. Foram necessárias duas guerras mundiais para que o capitalismo conseguisse sobreviver diante da profundidade de sua condição de modo de produção arcaico desafiado na segunda década do século XX por uma revolução socialista na Rússia e uma ofensiva mundial das novas forças revolucionárias do trabalho em alianças pouco estudadas com as forças sociais em dissolução, como o campesinato, e pelas novas populações de trabalhadores eventuais que se agigantam nas grandes metrópoles capitalistas.

A profundidade das mudanças impostas pelo desenvolvimento dos meios materiais e intelectuais nessa nova fase do desenvolvimento da humanidade ficou evidente também pelo seu impacto no campo teórico que colocou radicalmente em questão a capacidade do capitalismo e do liberalismo de resolver essas contradições. 


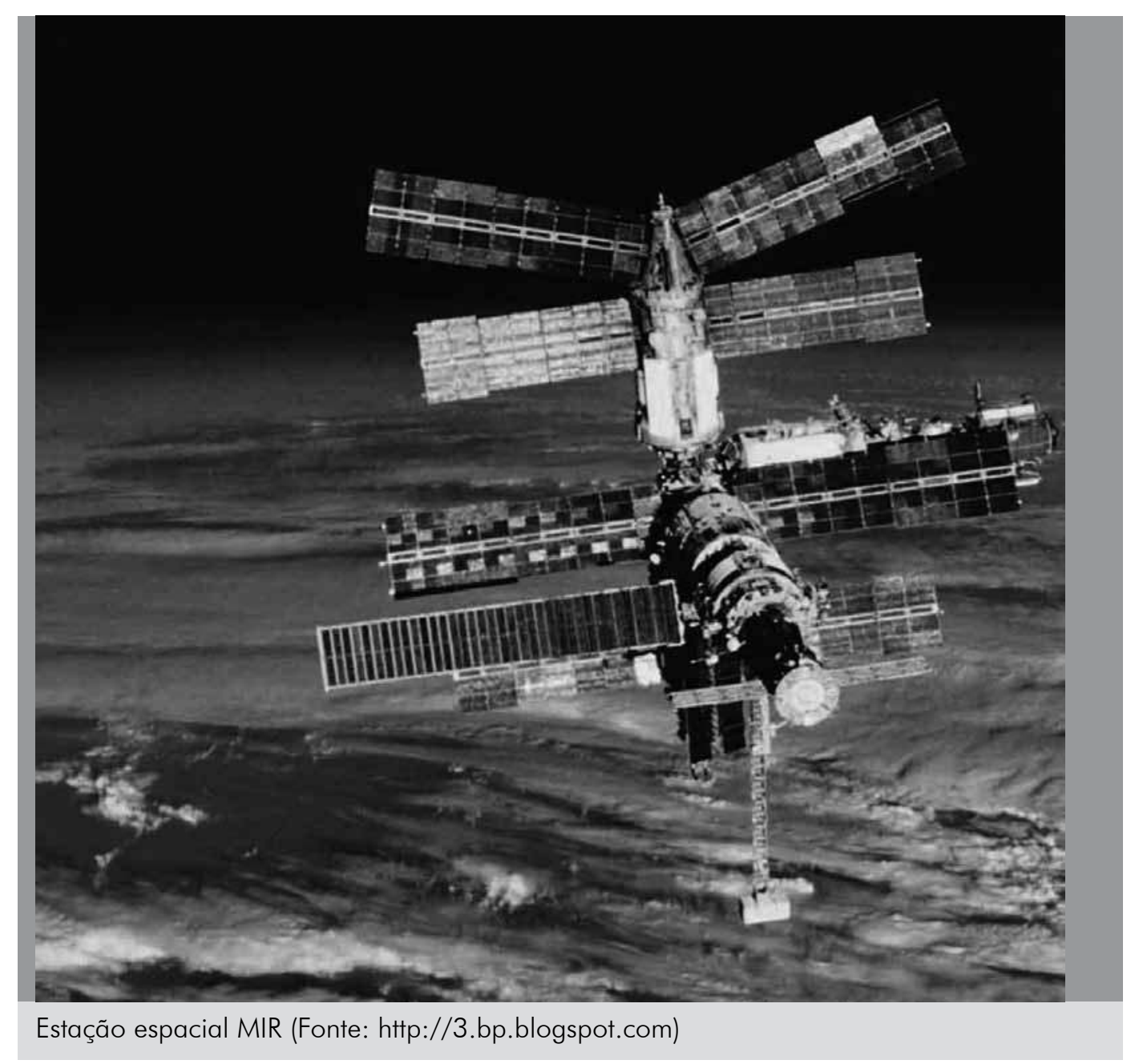

Mas devemos, sobretudo, compreender as manifestações materiais dessas mesmas contradições, através de uma guerra mundial em 1914-18 com a destruição de 30 milhões de vidas humanas. Ao mesmo tempo, a Revolução Mexicana (a partir de 1910) alertava para os limites do capitalismo nas regiões periféricas da economia mundial; a crise final do Império Otomano mostrava os limites do imperialismo que, na Índia, o frágil cidadão indiano Mahatma Gandhi fazia estremecer. Os vários avanços revolucionários importantes na Turquia, na Índia, na América Central, no Caribe e América do Sul, na China mostravam o conteúdo pós-liberal do novo momento histórico, marcado pelo surgimento vitorioso de uma revolução social que propunha a construção de uma nova formação social pós-capitalista na Rússia (esmagando a invasão de 23 países capitalistas, em uma guerra civil com 2 milhões de mortos, a qual seria o preço da resistência da revolução ou da fracassada reação das relações sociais ultrapassadas?).

Mas mais grave ainda foi a crise econômica mundial, iniciada em 1929, cujo desenlace posterior resultou na Segunda Guerra Mundial, que criou as condições para uma recuperação mundial das economias capitalistas através da utilização dos fantásticos avanços nas forças produtivas produzidos durante esses anos, que permitiram algo em torno de 70 milhões de mortos e a demonstração prática, em Hiroshima e Nagasaki, da capacidade destrutiva das armas nucleares que dominariam a hipótese de uma próxima guerra mundial. 
Não há dúvida de que o centro do poder econômico no pós II Guerra se encontrava nos Estados Unidos. Mas a derrota do nazismo tinha estado em mãos das tropas soviéticas, líder dos Aliados (Estados Unidos, Inglaterra, França (será?), a China do Kuomintang (com as tropas do exército vermelho no seu calcanhar) e algumas potências aliadas menores como o Brasil que não foram convocadas à reunião de Yalta. Era necessário deter a força militar, moral e ideológica que representava a União das Repúblicas Socialistas Soviéticas, que tinha resistido praticamente sozinha à invasão do mais poderoso exército do mundo e tinha entregue 20 milhões de mortos em defesa de sua nação e do regime econômico e social que adotara em uma profunda revolução social. Armou-se assim a Guerra Fria. Os (ou as) filósofos (as) políticos (as) a serviço da potência ganhadora inventaram um novo conto:

Segundo eles (as), o nazismo era uma modalidade de "totalitarismo" que representou uma ameaça para a humanidade (desta definição deveriam ser excluídos os filósofos que sustentaram a ideologia nazista como Heidegger ou os poetas fascistas como Ezra Pound, ou economistas conservadores como Schaft, etc.). Contudo o nazismo foi derrotado pelas tropas de outro "totalitarismo" (o soviético) que passava a ser o grande inimigo a enfrentar (ou destruir?).

Restava uma questão muito dura: essa potência "totalitária" tinha demonstrado uma superioridade não só de união de seu povo contra um rico e poderoso agressor; não só de estratégia militar; não só de disciplina militar e motivação ideológica e espiritual. Ela revelou também uma capacidade excepcional de desenvolver suas forças produtivas, já que não recebeu ajuda de nenhum de seus aliados... Segundo estas"teorias”, dever-se-ia duvidar da capacidade deste novo inimigo desenvolver as forças produtivas sem o "apoio" do Ocidente em cujas mãos continuavam o poder e a capacidade de desenvolvê-las. Não é aqui o lugar para narrar o fracasso desta proposta estratégica. Ela tentou deter a consolidação dos regimes impostos pelas tropas soviéticas na Europa Ocidental. Ela fracassou em sua tentativa de deter as ofensivas socialistas no mundo na Iugoslávia em 1945, na China em 1949, na Coreia em 1953, na Indochina (Vietnã do Norte) em 1954, derrota que se consolidou sobre toda a região (Vietnã do Sul, Laos e Camboja) em 1973, na Argélia em 1958, em Cuba em 1961, nas colônias portuguesas na década de 1970, a presença das tropas cubanas na África derrotando as forças armadas de África do Sul fortemente apoiada pelas nações pró-ocidentais.

Nem nos cabe detalhar aqui o avanço científico e tecnológico da URSS, que lançou a humanidade na conquista do Cosmos, mudando radicalmente o paradigma científico contemporâneo. Isso permitiu o surgimento do conceito de revolução científico-técnica, que mostrou, através do estudo excepcional do sociólogo tcheco Radovan Richta, que a hegemonia da ciência sobre a tecnologia anunciava um novo nível das forças produtivas que servia de base material de um novo modo de produção - o comunista. Assim como a revolução industrial criou as bases materiais para a implantação do modo de produção capitalista, a Revolução Científico -Técnica servirá de base material de um novo planeta fundado no planejamento e na cooperação ente indivíduos e povos.

O pensamento social ideologicamente comprometido com a salvação de um sistema social decadente e com uma ideologia ultrapassada se voltou então para a negação da existência de uma solução radical para as contradições apresentadas pelo capitalismo. $\mathrm{O}$ aumento exponencial dos excedentes gerados pela atividade produtiva 
contemporânea leva à necessidade do capital de se apoiar nos monopólios e na ação estatal cada vez mais ampla (um capitalismo de estado que se converte na força mais dinâmica e necessária para dominar esses gigantescos sistemas socioeconômicos que formam as bases da sociedade moderna).

O mais dramático não é apenas a orientação que o capital tem que dar a esses tremendos avanços na estrutura do conhecimento e nos produtos dela derivados (com especial ênfase no papel dos produtos militares cuja função e eficiência se medem concretamente por sua capacidade de destruição e na necessidade de manter um clima moral de enfrentamentos cada vez mais sangrentos entre os indivíduos, as classes, os grupos sociais, as instituições, os povos, as etnias, os gêneros, etc.).

Os desequilíbrios gerados pelas políticas neoliberais abriram caminho para um gigantesco sistema financeiro internacional sustentado pelo gigantesco excedente econômico produzido pelas novas forças produtivas, assim como pela apropriação deste excedente pelo Estado através não sòmente do poder de emissão de moedas, mas sobretudo da emissão de títulos de dívidas públicas que se estende a quase todas as nações capitalistas. Todas elas emitem dívidas gigantescas geradas por um poder de consumo super dimensionado ( o "consumismo" das classes dominantes e das chamadas classes médias, uma difícil aliada em expansão). Formam-se assim déficits fiscais permanentes e crescentes sempre cobertos por títulos de dívida pública cujas taxas de juros variam de acordo com a capacidade política dos bancos centrais justificarem essa monstruosa e irracional política macroeconômica.

Este quadro econômico não pode ser criado e se manter sem a transferência colossal de recursos "excedentes" (segundo a visão do sistema) criados pela revolução científico-técnica. Esta revolução parte do setor produtivo e de enormes avanços do setor de serviços para criar um mundo econômico financeiro completamente artificial. Essa transferência é feita direta ou indiretamente pelos Estados nacionais ou mesmo provinciais e locais. $\mathrm{O}$ capitalismo de Estado passa a ser o suporte fundamental dessa nova ordem capitalista hegemonizada pelo capital financeiro. Essa contradição mais geral leva a que os fatos e as políticas públicas contrariem drasticamente os princípios ideológicos do pensamento econômico dominante, disfarçado de "ciências exatas". Produz-se assim uma assincronia estrutural entre as construções teóricas e ideológicas e as práticas sociais.

Para superar essa contradição são necessárias novas políticas públicas e sobretudo um alerta sobre os limites desta intervenção estatal assim como uma tomada de consciência das várias forças sociais que terão de acordar do seu sonho reformista para se lançar à grande transformação econômica (automação e diminuição drástica da jornada de trabalho), social (construção de uma nova subjetividade baseada na solidariedade humana) e política (com respeito ao verdadeiro sentido da democracia: governo do povo e para o povo - participação não somente eleitoral mas também nas tarefas legislativas e executivas). Tudo isso supõe, no entanto um período histórico que combine o controle do Estado sobre o processo produtivo a serviço das grandes maiorias sociais, a ação do capitalismo de Estado articulada com a democracia na gestão das empresas e as formas coletivas de produção e a prestação de serviços (economia social) a serviço das necessidades da humanidade. As forças produtivas contemporâneas não somente estão prontas para este novo regime socioeconômico, mas o exigem. 
A crise atual do capitalismo mundial põe em manifesto a necessidade de assegurar o funcionamento do capitalismo através da emissão de trilhões de dólares estatais ou em forma de títulos das dívidas crescente. Essa política só é viável sob a forma de emissão de dólares ou outras moedas consideradas "seguras" por um sistema de instituições de seguro e avaliação comprovadamente corrupto. Ainda não está claro por quanto tempo e até que limites a sociedade contemporânea está disposta a sustentar essa política estatal - ocultada ideologicamente pelo neoliberalismo. Isto só será possível se os meios de comunicação forem obrigados a explicitá-la claramente, o que poderá ocorrer somente quando esses desequilíbrios atingirem níveis intoleráveis para o próprio modelo institucional existente.

A crise atual tem dois lados: em parte ela põe em evidência o fracasso da famosa capacidade de equilíbrio que poderia ser atingido através de um "livre mercado", que não existe e jamais poderia regular processos tão fundamentais. Mas, por outro lado, um manejo midiático impressionante da "crise" permite confundir as pessoas para justificar a violenta e deficitária intervenção estatal para subsidiar os amplos setores falidos do sistema - particularmente o setor financeiro - e impedir assim a "crise sistêmica" que, segundo eles, destruiria todos nós.

Em consequência, a crise é combatida com os mesmos mecanismos que a geraram. Pretende-se que a intervenção estatal e a regulação que faltaram no reino neoliberal sejam substituídas por umas "novas"intervenções e regulações a serviço de um equilíbrio anticíclico que só pode conduzir a novas crises ainda mais violentas.

O anúncio de um déficit fiscal de 1,7 trilhões de dólares previsto corretamente pelo presidente Obama para 2009 e a pretensa e inviável diminuição desse déficit para cerca de 700 bilhões em 2013 pôde ser combinado com uma recuperação moderada da economia estadunidense. É evidente que uma recuperação fundada nestes mecanismos será restringida e vacilante, aprofundando a crise da hegemonia mundial dos Estados Unidos e de sua moeda. O caso japonês na década de 90 fica como referência fundamental para os próximos 7 a 9 anos. E é bom lembrar que o Japão conseguiu reduzir o valor internacional de sua moeda drasticamente desde 1996 e manteve uma taxa de juros negativa durante esse período. No entanto, não conseguiu restabelecer um período sólido de crescimento econômico.

É claro também que, enquanto se mantiver esse quadro de "recuperação rasante" com custo alto na Tríade (EUA, Europa e Japão) as economias emergentes estarão em ascensão, apoiadas na expansão de seus mercados internos através de distribuições de renda mais ou menos profundas como resultado de uma ascensão crescente dos movimentos sociais e suas vitórias políticas mais ou menos importantes.

Podemos esperar que os próximos 10 anos sejam de avanço social e econômico com maior ou menor avanço político, dependendo da consciência das forças sociais emergentes e da capacidade de suas lideranças políticas de expressar e sintetizar suas necessidades e aspirações. Acho que nosso livro sobre auge e decadência do neoliberalismo e os demais da trilogia sobre o mundo contemporâneo poderão ajudar nesta tarefa. $\mathrm{O}$ fato de que foram traduzidos e publicados em espanhol, e particularmente ao mandarim, o idioma nacional chinês, e publicado pela editorial da Academia de Ciências Sociais muito me orgulha. Gosto de pensar que a vanguarda política da China pode dialogar com meu esforço teórico, como o vem fazendo desde a tradução ao mandarim de meu livro Imperialismo y Dependencia em 1992, seguida de 2 reedições e a publicação de 5 livros mais. 
Proponho-me a me dedicar agora, com vários colegas, a formular as alternativas que se desenham através de governos progressistas - que se formaram a partir da decadência do neoliberalismo e da ação cada vez mais ativa e consciente dos movimentos sociais que se libertam pouco a pouco do terror paralisante que os debilitou durante as ditaduras. Nesse contexto, insiro minha cooperação com o projeto de UNESCO sobre "Repensar a América Latina", que procura articular uma visão sistemática das políticas de desenvolvimento social na América Latina.

Ao mesmo tempo, dedico-me a elaborar um novo esforço crítico sobre o conceito de desenvolvimento, vinculando-o ao avanço do processo civilizatório em curso, o que rompe com a tentativa (hoje definitivamente questionada) de impor ao mundo a ideia de que a Europa e seu seguidor histórico, os Estados Unidos, representam o modelo da civilização em geral.

A noção de desenvolvimento não pode mais servir a este projeto imperialista e deve sim servir de instrumento para planejar as condições de surgimento e implantação de uma verdadeira civilização planetária, que se apoiará nas ricas experiências civilizatórias de todos os povos do planeta e definitivamente no respeito à diversidade cultural que a história produziu. Esse esforço democrático e pluralista nos permitirá utilizar a sabedoria das diversas civilizações, que emana de ambientes ecológicos diversos e das soluções criativas encontradas por seus habitantes, para conseguir uma articulação virtuosa entre a humanidade e a natureza que tanto precisamos diante de uma crise ambiental planetária extremamente grave que vivemos sob o caos social promovido pelas formações sociais fundadas no modo de produção capitalista.

Procuramos sobretudo dar continuidade à "crítica da economia política" proposta nos Grundrisse e na coleção de livros com este mesmo nome, iniciada com a publicação de $O$ Capital de Karl Marx, cujos 3 volumes representavam apenas o primeiro livro dos 6 que compunham este ambicioso projeto científico. Faz-se necessário estendê-la ao complexo processo histórico do mundo contemporâneo, o que é um trabalho teórico mais abstrato, mas muito necessário para orientar nossa prática atual, trabalho cujos princípios gerais espero também oferecer ao público leitor muito em breve. 